\title{
Corrigendum to "Multiple gas reservoirs are responsible for the gas emissions along the Marmara fault network"
}

\author{
Ruffine Livio ${ }^{1,{ }^{*}}$, Donval Jean-Pierre ${ }^{1}$, Croguennec Claire ${ }^{1}$, Burnard Pete ${ }^{2,8}$, Lu Hailong ${ }^{3}$, \\ Germain Yoan ${ }^{1}$, Legoix Ludovic N. ${ }^{1,4}$, Bignon Laurent ${ }^{5}$, Çağatay M. Namık ${ }^{6}$, Marty Bernard ${ }^{2}$, Madre \\ David $^{2}$, Pitel-Roudaut Mathilde ${ }^{1}$, Henry Pierre ${ }^{7}$, Géli Louis ${ }^{1}$
}

${ }^{1}$ IFREMER, Département Ressources physiques et Ecosystèmes de fond de Mer (REM), Unité des Géosciences Marines, 29280 Plouzané, France

${ }^{2}$ Centre de Recherches Pétrographiques et Géochimiques, Unité Mixte de Recherches CNRS \&

Université de Lorraine, F-54500 Vandoeuvre-lès-Nancy, France

${ }^{3}$ Peking University, Department of Energy \& Sciences, College of Engineering, Beijing 100871

${ }^{4}$ GEOMAR Helmholtz Centre for Ocean Research Kiel, Wischhofstr. 1-3, D-24148 Kiel, Germany

${ }^{5}$ IFREMER, Département Ressources physiques et Ecosystèmes de fond de Mer (REM), Unité des Recherches et Développements Technologiques, 29280 Plouzané, France

${ }^{6}$ Istanbul Teknik University, Faculty of Mines, EMCOL and Department of Geological Engineering, TR34469 Istanbul, Turkey

${ }^{7}$ Aix-Marseille Univ., CNRS, IRD, Coll. France, CEREGE, Aix-en-Provence, France

* Corresponding author : Livio Ruffine, email address : livio.ruffine@ifremer.fr

\begin{abstract}
:
The authors regret a mistake on the value of $\delta 13 \mathrm{C}$ of methane for one of the investigated gas samples. This concerns sample MRS-DV3-PE03, taken as end member and for which the correct methane $\delta 13 \mathrm{C}$ value is $-41.9 \%$ and not $-34 \%$. The sample was collected at in situ pressure ( 100 bars) from a CO2rich seep, in a liquid state. The mistake likely results from a partial extraction (i.e. done by expansion of the sampler volume to allow vaporization) of the pressurized sample for subsampling. Additional analyses have been carried out from fully vaporized samples. This error has resulted in updating the geochemical diagrams used for the discussion, and revising both the gas origin for sample MRS-DV3PE03 and the section entitled "Delineation of sources, reservoirs or migration pathways, and estimation of level of mixing". The conclusion of the manuscript is unchanged. The authors would like to apologize for any inconvenience caused.
\end{abstract}




\section{Consequently, the following changes have been made:}

\section{Results}

The range of methane carbon $\left(\delta^{13} \mathrm{C}\right)$ has been changed as follows:

The carbon $\left(\delta^{13} \mathrm{C}\right)$ and hydrogen $(\delta \mathrm{D})$ stable isotope compositions of methane range between -41.9 and $-66.1 \%$, and -253 and $-174 \%$, respectively.

\section{Discussion}

The error on the methane $\delta^{13} \mathrm{C}$ for sample MRS-DV3-PE03 implies revising the sections dealing with its source, the overprinting processes as well as the source mixing as follows:

\section{Dive MRS-DV3 at the western flank of Tekirdağ Basin}

The gas sources supplying the seeps at this area have not been identified from previous cruises. From the molecular composition of sample MRS-DV3-PE03, it appears clearly that the seep is primarily supplied by a $\mathrm{CO}_{2}$-rich source as this compound accounts for more than $97 \%$-mol of the total gases. Moreover, it is likely that the $\mathrm{CO}_{2}$-rich source also supplies to a lesser extent the seep represented by sample MRS-DV3-PE02 as the amount of this compound is relatively high $\left(\sim 8 \%\right.$-mol). The $\delta^{13} \mathrm{C}$ of carbon dioxide and methane for MRSDV3-PE03 reflects gases originating from a deep-seated source, where methane is of thermogenic origin and carbon dioxide may derive either from the mantle or carbonate dissolution (Toutain and Baubron, 1999; Waseda and Iwano, 2008). The He isotopic composition was not measured for this sample, but those from the nearby samples MRS-DV3PE01 and MRS-DV3-PE06 show the highest ${ }^{3} \mathrm{He} /{ }^{4} \mathrm{He}$ values recorded so far for the whole area (Table 3). These values are indicative of gases originating from the mantle, and this is in agreement with measurements made by both Burnard et al. (2012) at the same area, and Doğan et al. (2009) onshore along the Ganos (Kaziköy-Saros) fault. Thus, the $\mathrm{CO}_{2}$-rich gases emitted here result from the degassing of the mantle. The $\mathrm{CO}_{2}$-rich seep and the mantlederived He-rich seep are separated by $\sim 2200 \mathrm{~m}$. This distance corresponds to the lower estimate of the influence perimeter of the $\mathrm{CO}_{2}$-rich source.

Except for methane, the two samples MRS-DV3-PE02 and MRS-DV3-PE03 have very similar isotopic compositions for the $\mathrm{C}_{2+}$ fraction. Therefore, the lighter methane $\delta^{13} \mathrm{C}$ measured for MRS-DV3-PE02 indicates a higher contribution from a ${ }^{13} \mathrm{C}$-depleted methane source. Samples MRS-DV3-PE01 and MRS-DV3-PE06 were taken at a tension gash on the seafloor at the site called Boris Bubbler (Géli et al., 2008; Henry, 2007; Tary et al., 2012) where the two most vigorous gas seeps were found (Ruffine et al., In this issue). The seeps 
were respectively named Chnikov and Boubouns by the scientific team. They exhibit very similar molecular and isotopic compositions; except for the carbon dioxide, which is more enriched in ${ }^{13} \mathrm{C}$ for MRS-DV3-PE06. Both samples are characterized by ${ }^{13} \mathrm{C}$-enriched $\mathrm{n}$ butane and $\mathrm{n}$-pentane, and ${ }^{13} \mathrm{C}$-depleted methane. The isotopic signatures of all these four above-mentioned components, methane, $\mathrm{CO}_{2}$, n-butane and n-pentane, are indicative of thermogenic gases having undergone hydrocarbon biodegradation followed by secondary methanogenesis. Interestingly, these two seeps have the highest He isotope ratios. Thus, the emitted gases at these two vigorous seeps result from a mixture of thermogenic, microbial and mantle-derived abiotic gases. The deep abiotic source contributing to the gas supply is possibly a source of energy necessary for thermogenic gas generation in this area. Sample MRS-DV3-PE09 was taken in an area where a huge amount of oil droplets was seeping out at the seafloor (Ruffine et al., In this issue). Surprisingly it corresponds to the driest sample collected along the Ganos fault segment. The propane is extremely enriched in ${ }^{13} \mathrm{C}$, being indicative of biodegradation, whereas the $\delta^{13} \mathrm{C}$ of carbon dioxide is very light. These observations hold true for sample MRS-DV3-PE04, which exhibits the most ${ }^{13} \mathrm{C}$-enriched propane amongst all the visited seeps. Thus, it is likely that the seeps corresponding to samples MRS-DV3-PE04 and MRS-DV3-PE09 are mixes of a thermogenic source with a microbial source from secondary methanogenesis. Unexpectedly, the low $\delta^{13} \mathrm{C}$ values of $\mathrm{CO}_{2}$ for these two samples are typical of organic source. Such low values likely indicate that the hydrocarbon biodegradation overwhelms secondary methanogenesis. This is also supported by the high values of $\delta^{13} \mathrm{C}$ for propane and n-butane.

Moreover, samples MRS-DV3-PE04 and MRS-DV3-PE09 exhibit very different hydrocarbon isotopic signatures. This evidences two different reservoirs or two different migration pathways, which are also different from the thermogenic reservoirs supplying the two seeps represented by samples MRS-DV3-PE01 and MRS-DV3-PE06. Accordingly, at least four thermogenic gas reservoirs or migration pathways contribute to emissions along this $\sim 5-\mathrm{km}$ long fault segment (Table 4). They are sourcing the seeps represented by MRS-DV3-PE04, MRS-DV3-PE09, MRS-DV3-PE02 and MRS-DV3-PE03, and MRS-DV3-PE01 and MRSDV3-PE06, respectively. Except for the seep represented by samples MRS-DV3-PE02 and MRS-DV3-PE03, all thermogenic sources are undergoing hydrocarbon biodegradation followed by secondary methanogenesis, which provides an additional microbial methane source. Besides, a mantle-derived $\mathrm{CO}_{2}$ and ${ }^{3} \mathrm{He}$ source supplies the seeps represented by MRS-DV3-PE01, MRS-DV3-PE02, MRS-DV3-PE03 and MRS-DV3-PE06, and a microbial 
source provides methane from primary methanogenesis to the seeps described by MRS-DV3PE02 and MRS-DV3-PE03.

\section{Overprinting of gas-to-source rock correlations by secondary alteration processes}

In the previous section, we have shown that most of the seeps emit gases, which are mixes of thermogenic gases, microbial gases and mantle-derived abiotic gases. Our results also show that hydrocarbon biodegradation followed by secondary methanogenesis is widespread on the Central and Western highs, as well as at the western flank of the Tekirdağ Basin. It is important to emphasize that such processes have not been observed for any of the 11 onshore natural-gas fields investigated in previous studies (Gürgey et al., 2005; Hoşgörmez and Yalçin, 2005; Hoşgörmez et al., 2005).

These two post-genetic alterations, hydrocarbon biodegradation and secondary methanogenesis, can considerably change the isotopic signature of the gases expelled from the source rock. Berner and Faber (1996) have proposed an empirical model to link the maturity and types of organic matter of source rock with the carbon isotope signature of methane, ethane and propane (Fig. 5a and 5b). The application of such a model to our sample clearly highlights the implication of hydrocarbon biodegradation and secondary methanogenesis in modifying original methane and propane isotopic signatures. Fig. 5b shows that the propane for all samples from the Central High and two samples from the western flank of the Tekirdağ Basin (MRS-DV3-PE04 and MRS-DV3-PE09) are severely biodegraded, and Table 2 shows that this is also the case for the n-butane. In addition, severe n-butane and n-pentane biodegradation also occurs for the seeps represented by samples MRS-DV3-PE01 and MRS-DV3-PE06. Thus, secondary alteration processes have deeply modified the original isotopic signatures of the gas components, making the evaluation of hydrocarbon maturity difficult.

\section{Delineation of sources, reservoirs or migration pathways, and estimation of the level of mixing}

At the western flank of the Tekirdağ Basin, an abiotic $\mathrm{CO}_{2}$-rich source, a primary microbial gas source and four thermogenic reservoirs or migration pathways for which three are associated with secondary microbial gases have been identified. We also confirmed, in agreement with Bourry et al. (2009), that the two highs are characterized by emissions of gases that are primarily of thermogenic origin, but with an admixture of microbial gases from secondary methanogenesis. However, it is important to specify that our data cannot allow for 
a clear determination of the location where secondary methanogenesis occurs. The short distance between the seeps would suggest that secondary methanogenesis mainly occurs during migration instead of at several different reservoirs. However, there is a lack of data documenting the plumbing system of the sedimentary column and showing the location of the potential reservoirs to support such a conclusion. Likewise, we are not able to discuss the distance between sources and seeps and they can be kilometers away from each other.

Nevertheless, molecular and isotopic compositions clearly show that the seeps from the two highs are supplied from two distinct thermogenic sources. Moreover, on the Central High, sample MRS-DV1-PE03 is characterized by lighter methane $\delta^{13} \mathrm{C}$ and heavier carbon-dioxide $\delta^{13} \mathrm{C}$ compared to the two other samples (Table 2). Such differences suggest either a higher admixture of microbial gases or an isotopic fractionation during migration due to gas diffusion (Prinzhofer and Pernaton, 1997). Because gas ebullition is the dominant transport process at gas seeps, we believe that different extents of biodegradation followed by secondary methanogenesis is the more plausible explanation for the difference in $\delta^{13} \mathrm{C}$ for methane, and this may be indicative of two different reservoirs or migration pathways.

In an attempt to further unravel the gas sources, differentiate reservoirs or migration pathways, and estimate their level of mixing when possible, we applied the diagram proposed by Chung (Chung et al., 1988) to our gas samples. It expresses the $\delta^{13} \mathrm{C}$ of the hydrocarbon components as a function of their reciprocal number of carbon atoms for the hydrocarbons (Fig. 6). This diagram is usually applied to identify pristine and altered natural gas, as well as mixing (Gürgey et al., 2005; Hoşgörmez et al., 2005). Samples MRS-DV3-PE02 and MRSDV3-PE03 from the western flank of the Tekirdağ Basin are the only ones to share the same isotopic signature for ethane, propane and n-butane with the pristine thermogenic KuzeyMarmara natural gas field (Gürgey et al., 2005; Hoşgörmez and Yalçin, 2005; Hoşgörmez et al., 2005). Such a result indicates that these two samples do not present evidence of any significant hydrocarbon biodegradation, and this is supported by Fig.6. Thus, taking the methane $\delta^{13} \mathrm{C}$ values of the pristine natural gas and MRS-DV4-PE02 as thermogenic and microbial end-members, respectively, and applying the equations expressed below it becomes possible to estimate the contribution of each gas source for several of our collected samples (Table 4):

$$
\begin{aligned}
& \mathrm{TC}=\left(\delta^{13} \mathrm{C}_{\text {sample }}-\delta^{13} \mathrm{C}_{\mathrm{MC}}\right) /\left(\delta^{13} \mathrm{C}_{\mathrm{TC}}-\delta^{13} \mathrm{C}_{\mathrm{MC}}\right) \\
& \mathrm{MC}=\left(\delta^{13} \mathrm{C}_{\text {sample }}-\delta^{13} \mathrm{C}_{\mathrm{TC}}\right) /\left(\delta^{13} \mathrm{C}_{\mathrm{BC}}-\delta^{13} \mathrm{C}_{\mathrm{TC}}\right)
\end{aligned}
$$


We voluntarily took sample MRS-DV4-PE02 as microbial end-member even if it does not present the lighter methane $\delta^{13} \mathrm{C}$. The reason is that it is more representative of the $\delta^{13} \mathrm{C}$ of our measured dataset for microbial methane. In addition, its $\delta^{13} \mathrm{C}$ value is close to the value of $61.48 \%$ calculated by Gurgey et al. (2005). Microbial gas-dominant samples with lighter methane $\delta^{13} \mathrm{C}$ have likely undergone diffusion-driven fractionation during their migration (Prinzhofer and Pernaton, 1997), or come from different substrates. Fig.6 also shows that the samples collected from the Western High and the gases constituting the Kuzey-Marmara natural gas field have very close values of $\delta^{13} \mathrm{C}$ for ethane and propane. A linear extrapolation from the ethane and $\mathrm{n}$-butane $\delta^{13} \mathrm{C}$ to the ordinate axis on the Chung diagram leads to a modeled pure-thermogenic methane $\delta^{13} \mathrm{C}$ of $\sim-34 \%$ (Fig. 6). One can clearly see that the latter $\delta^{13} \mathrm{C}$ value corresponds to the measured value for the pristine Kuzey-Marmara natural gas field.

Table 4 summarizes the estimated level of mixing between the identified gas sources. The seeps that are located on the highs and at the western flank of the Tekirdağ Basin are dominantly composed of thermogenic gases. The $\mathrm{CO}_{2}$-rich source contributes to $97.6 \%$-mol of the gas seep represented by sample MRS-DV3-PE03 from the western flank of the Tekirdağ Basin, the remaining being a mixture of a pristine natural gas at $1.75 \%$-mol with primary microbial gases at $0.65 \%$-mol. Based on the $\mathrm{CO}_{2}$ content, the seep related to sample MRS-DV3-PE02 is composed of around $8 \%$ of mantle-derived gases; the remaining gases is composed of $20 \%$-mol of microbial gases from primary methanogenesis and $72 \%$-mol of pristine thermogenic gases (Table 4). Samples MRS-DV3-PE04 and MRS-DV3-PE09 have thermogenic methane contributions of $\sim 30$ and $18 \%$, respectively. The low $\mathrm{CO}_{2}$ concentrations for samples MRS-DV3-PE01 and MRS-DV3-PE06 suggest that the mantle gas contribution is primarily helium. When considering only hydrocarbons, $\sim 39 \%$-mol of gases are of thermogenic origin and 61\%-mol are from secondary methanogenesis.

Samples MRS-DV2-PE02 and MRS-DV2-PE03 from the Western High are characterized by a lighter methane $\delta^{13} \mathrm{C}$ compared to the value of $-34.0 \%$ of the pristine natural gas (Fig. 6) and a ${ }^{13} \mathrm{C}$-enriched carbon dioxide, which indicates biodegradation of hydrocarbons followed by secondary methanogenesis. A high $\delta^{13} \mathrm{C}$ was also reported for the carbonate crust sampled on the mud volcanoes nearby (Cagatay et al., Accepted for this issue; Crémiere et al., 2012). Because these samples have similar methane $\delta^{13} \mathrm{C}$, our best explanation to the observed differences on their molecular composition is that the $\mathrm{C} 2 / \mathrm{C} 1$ ratio is controlled by hydrate formation and dissociation. Nevertheless, their isotopic composition indicates relatively 
moderate biodegradation (Fig. 6) and the calculated microbial methane contribution is of 34 $\%$ for both samples, the remaining being thermogenic gases. Our calculation method cannot be applied to the gas samples from the Central High as the isotopic signatures of the compounds are too overprinted to make any estimation of the $\delta^{13} \mathrm{C}$ of the thermogenic end member. The samples collected from the fault segments located at the southeastern flank of the Tekirdağ Basin and in the Çınarcık Basin are overwhelmingly composed of microbial gases generated from primary methanogenesis. 
Table 4: Estimation of the level of mixing between the identified methane sources.

\begin{tabular}{|c|c|c|c|c|c|}
\hline Sample name & Site location & $\begin{array}{c}\text { Thermogenic } \\
\text { gases }\end{array}$ & $\begin{array}{l}\text { Microbial gases from secondary } \\
\text { methanogenesis }\end{array}$ & $\begin{array}{c}\text { Microbial gases from } \\
\text { primary } \\
\text { methanogenesis }\end{array}$ & $\begin{array}{c}\mathrm{CO}_{2} \text {-rich mantle-derived } \\
\text { source }\end{array}$ \\
\hline $\begin{array}{l}\text { MRS-DV1-PE02 } \\
\text { MRS-DV1-PE03 }\end{array}$ & Central High & $\begin{array}{l}\text { primarily } \\
\text { primarily }\end{array}$ & $\begin{array}{l}\text { present } \\
\text { present }\end{array}$ & $\begin{array}{l}\text { undetermined } \\
\text { undetermined }\end{array}$ & $\begin{array}{l}0 \\
0\end{array}$ \\
\hline MRS-DV2-PE01 & Western & 66 & 34 & & 0 \\
\hline MRS-DV2-PE02 & High & 66 & 34 & & 0 \\
\hline MRS-DV3-PE01 & & $\sim 39^{\mathrm{a}}$ & $\sim 61^{\mathrm{a}}$ & 0 & Present at low level \\
\hline MRS-DV3-PE02 & Western & 72 & 0 & 20 & 8 \\
\hline MRS-DV3-PE03 & flank & 1.75 & 0 & 0.65 & 97.6 \\
\hline MRS-DV3-PE04 & Tekirdağ & $\sim 30$ & $\sim 70$ & Undetermined but low & 0 \\
\hline MRS-DV3-PE06 & Basin & $\sim 39^{\mathrm{a}}$ & $\sim 61^{\mathrm{a}}$ & 0 & Present at low level \\
\hline MRS-DV3-PE09 & & $\sim 18$ & $\sim 82$ & Undetermined but low & 0 \\
\hline MRS-DV4-PE02 & Southeastern & $\sim 0$ & 0 & $\sim 100$ & 0 \\
\hline MRS-DV4-PE07 & flank & $\sim 0$ & 0 & $\sim 100$ & 0 \\
\hline MRS-DV4-PE08 & $\begin{array}{l}\text { Tekirdağ } \\
\text { Basin }\end{array}$ & $\sim 0$ & 0 & $\sim 100$ & 0 \\
\hline MRS-DV5-PE01 & & $\sim 1$ & 0 & $\sim 99$ & 0 \\
\hline MRS-DV5-PE02 & Çınarcık & $\sim 2$ & 0 & $\sim 98$ & 0 \\
\hline MRS-DV5-PE03 & Basin & $\sim 0$ & 0 & $\sim 100$ & 0 \\
\hline MRS-DV5-PE04 & & 6 & 0 & 94 & 0 \\
\hline
\end{tabular}

The thermogenic sources are different for the Western High and the Central High, and three other thermogenic sources are connected to the seeps in the Tekirdag Basin represented by the samples MRS-DV3-PE01 and MRS-DV3-PE06, MRS-DV3-PE02 and MRS-DV3-PE03, MRS-DV3-PE04 and MRS-DV3-PE09, respectively. ${ }^{a}$ Estimate
when
considering
only the hydrocarbon
sources
(i.e.
normalized
to
thermogenic
and
microbial
sources). 

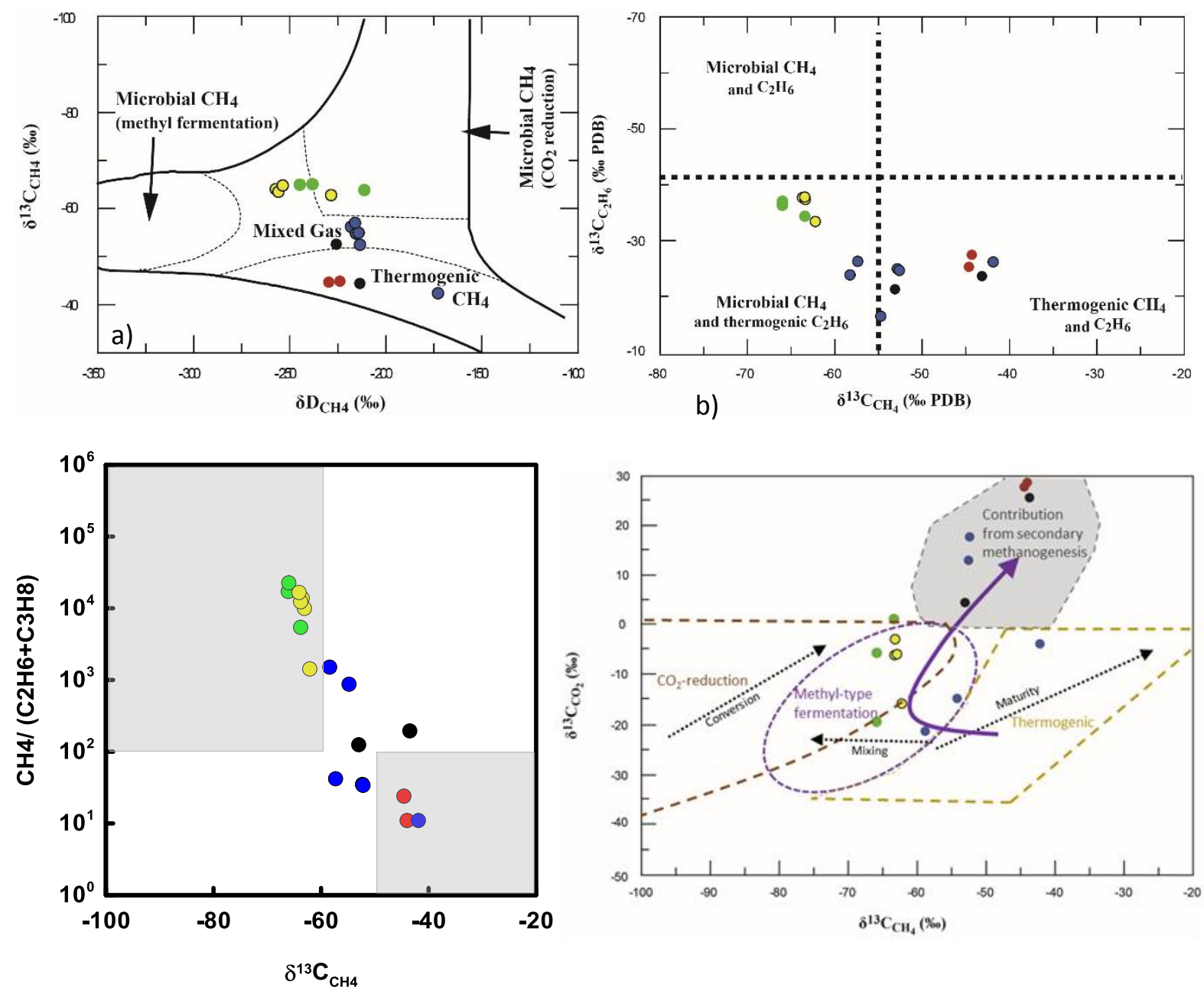

c)

d)

Figure 4: a) Diagram of methane hydrogen and carbon stable isotope compositions for the studied venting gases (modified after Schoell, 1983 and Whiticar, 1999); b) Diagram of carbon stable isotope composition of methane vs. ethane for the study sites (modified after Milkov, 2005); c) Diagram of methane carbon stable isotope composition vs. ethane and propane molecular compositions for the studied venting gases (modified after Bernard, 1978); ); d) Diagram of carbon stable isotope composition of methane vs. carbon dioxide for the study sites (modified after Milkov, 2011). See Figure 3 for color code. 

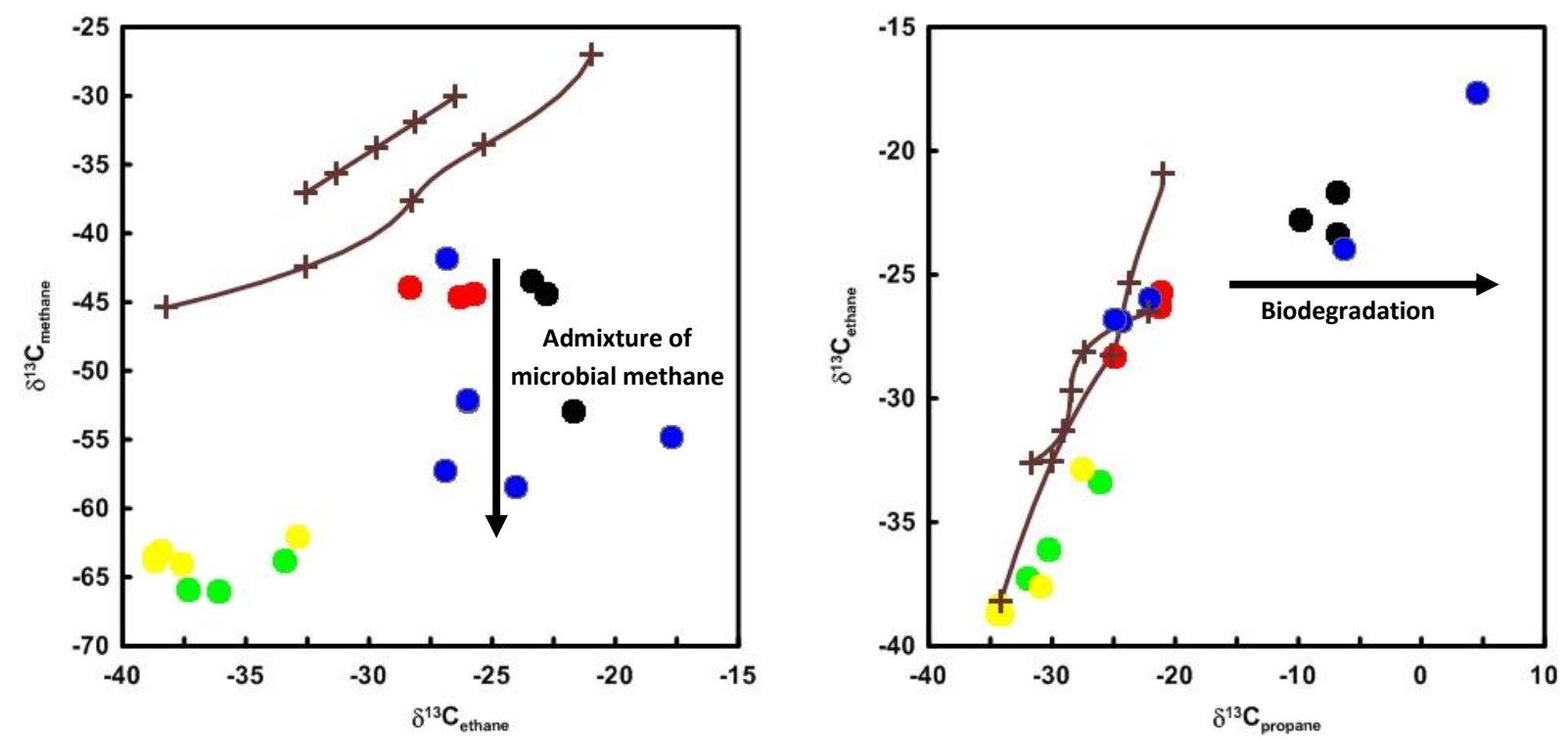

Figure 5: Maturity diagrams based on the $\delta^{13} \mathrm{C}$ of methane, ethane and propane for the gas samples. Isotopic composition of the marine (type II) and terrestrial (type III) kerogens was set to $-29 \%$ and $30 \%$, respectively (after Hoşgörmez et al. (2005) and Gürgey et al. (2005)). See Figure 3 for color code. 


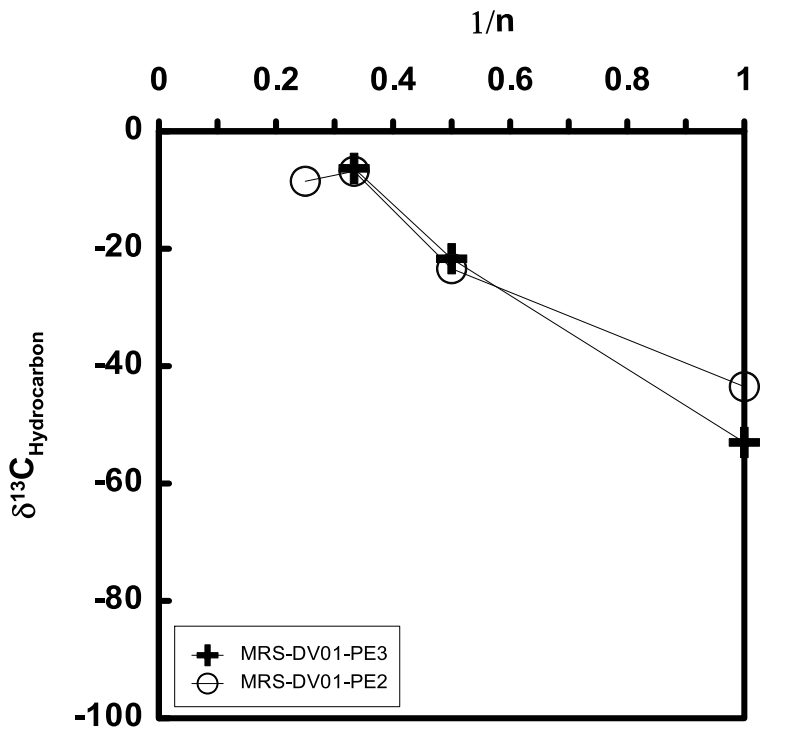

a)

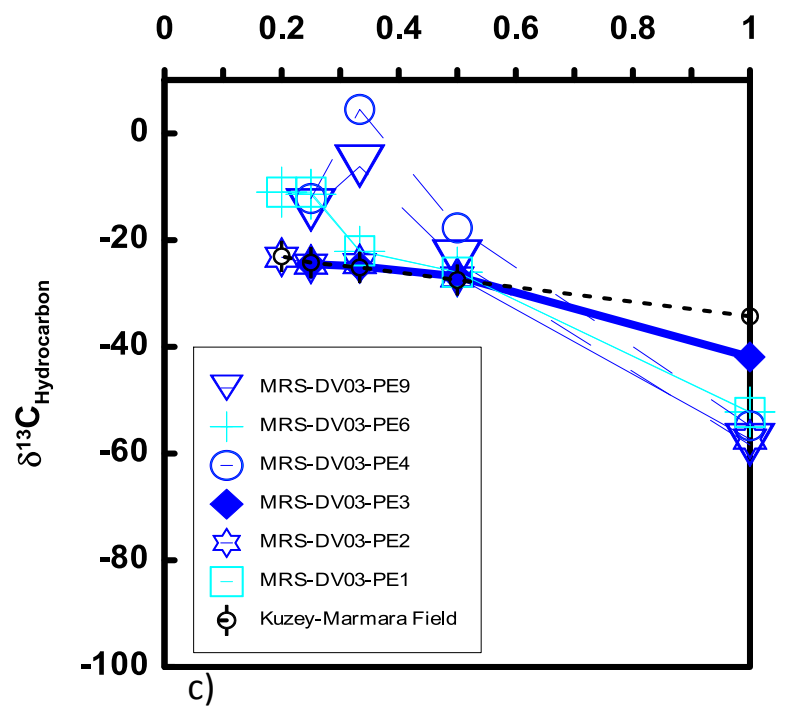

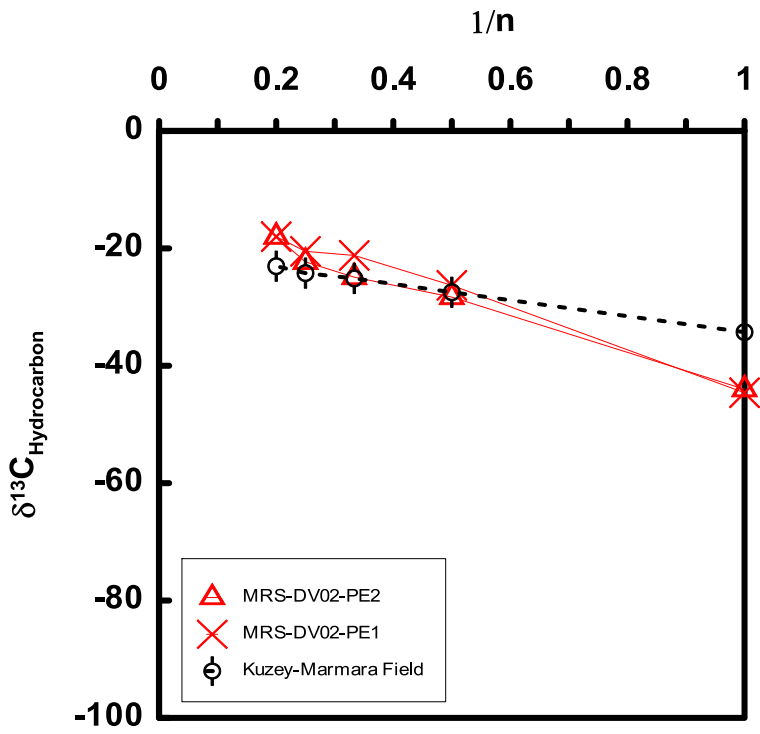

b)

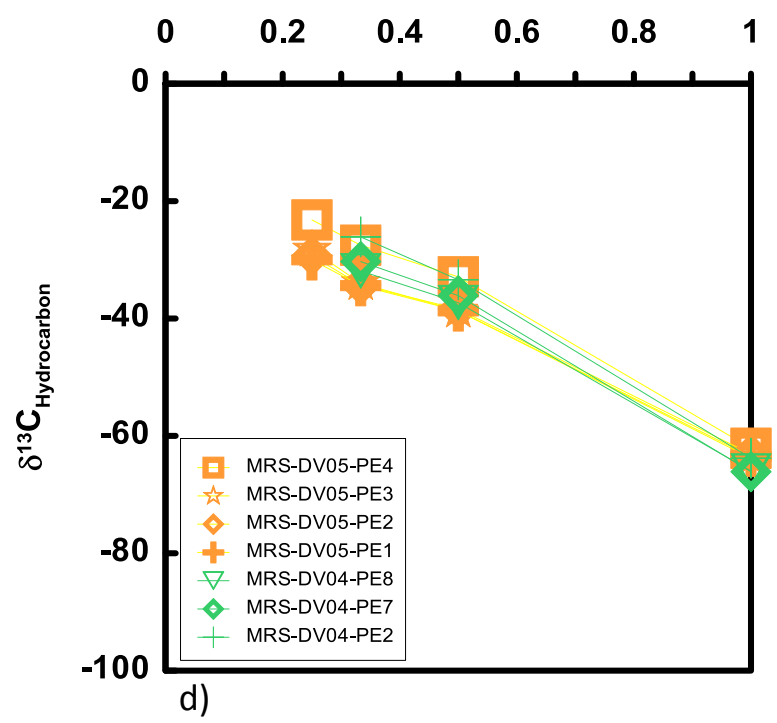

Figure 6: Chung diagram (Chung et al., 1988) applied to our seeps gases: a) Central High, b) Western High, c) The western flank of Tekirdag Basin, d) The southeastern flank of Tekirdag Basin (green) and Cinarcik Basin (yellow). 